\title{
Application of Environmental Friendly Material R32/R1234ze in Heat Pump Water Heater Ying Wang ${ }^{1, a^{*}}$, Fang Wang ${ }^{1, b}$, Hongqun Chen ${ }^{1, \mathrm{c}}$, Fang $\mathrm{Li}^{1}$, Siyu $\mathrm{Li}^{1}$ \\ ${ }^{1}$ University of Shanghai for Science and Technology, Shanghai 200093, China \\ a18817570601@163.com, bwang1996930@163.com, 'chenhonqun@163.com
}

\begin{abstract}
Keywords: Environmental friendly material, Mixed refrigerant, Heat pump water heater, Performance testing.
\end{abstract}

\begin{abstract}
With the refrigeration equipment working medium transition from high GWP to low, it is significant to study the environmental friendly refrigerant to protect the environment and avoid the greenhouse effect. Through theoretical analysis and experimental study of R32 and R1234ze mixtures, this paper provides the reference for the application of mixed refrigerant in the heat pump water heater. Based on REFPRO 9.0 and KW2 model parameters, this paper calculated the thermophysical properties of mixing refrigerant R32/R1234ze; according to the heat pump water heater test standard, figured out cycle performance of mixed refrigerant in different ratios. The results showed that the optimal mixture ratio is $0.7 / 0.3$. Applying this ratio, in different operating conditions, the refrigerant performance tests are conducted in comparison with R410A on heat pump water heaters. The results indicate that, with the R32 and R1234ze refrigerant mixture under the ratio of 0.7/0.3, the compressor power consumption and discharge pressure are lower, which is conducive to the safe and stable operation of the water heater unit. But the system COP is higher than R410A, and the decline rate of COP is lower when the temperature is higher than the standard conditions. Therefore, the mixed refrigerant is feasible to replace R410A.
\end{abstract}

\section{Introduction}

In recent years, the climate change and environmental damage caused by the greenhouse gases have attracted increased attention to the environmental protection. Heat pump water heater has been widely concerned with high efficiency and environmental protection. Currently the heat pump systems are widely using R22 as refrigerant, which is a HCFCs type refrigerant and the main chemical substance that damages the ozone layer and generates greenhouse effect. < Montreal Protocol > requires developed countries to completely phase out HCFCs in 2020, and developing countries to phase out HCFCs in 2030 [1]. R410A is a substitute of R22. While its ODP is zero, the GWP value is 1924.The F-gas regulations are ended by the European Union in 2014, stipulate that refrigerators and freezers for home use, and those for business use, which contain HFCs and whose GWP value are above 150, are banned from market since January 1st 2015 and January 1st 2022 respectively [2]. DuPont Company and Honey Well Company jointly developed the new refrigerant R1234ze, a kind of environmental friendly refrigerants, with 0 ODP value and 6 GWP value, and have a short atmospheric lifetime. But its latent heat is small and its evaporation pressure and thermal conductivity is low, which will lead to a decline in system performance coefficient. However, R32 has good thermal properties and transmission properties, whose theoretical COP and volumetric refrigerating capacity are higher [3-4], and can be refrigerant mixtures to improve the R1234ze thermodynamic and transport properties [5]. Md. Anowar Hossain etc. have conducted the experiment of single tube flow heat transfer under the evaporation and condensation condition on the R32 and R1234ze mixed refrigerants [6-7].

In this paper, the operation characteristics of the whole system are studied with the performance test of the heat pump water heater under different conditions, and are based on the theoretical analysis of the thermal physical properties of the mixture and the optimum mixture ratio discussion for the refrigeration cycle. 


\section{Theoretical Calculation}

Rule of Mixture. At present, many scholars have studied the thermodynamic equation of state of R1234ze and its mixtures. The state equation for the Helmholtz energy have been widely applied to description of refrigerant thermodynamic properties, Akasaka $\mathrm{R}$ [8] studied the equation of state model that is based on Helmholtz energy and fitted the parameters of the model, the Helmholtz energy is expressed as

$$
\frac{a}{R T}=\alpha=\alpha^{i d m i x}+\alpha^{E}
$$

where, $a$ is the molar Helmholtz energy of a mixture, $\mathrm{T}$ is the mixture temperature, $R=8.314472 \mathrm{~J} /(\mathrm{mol} \cdot K)$ is the universal gas constant, idmix is the ideal mixture contribution, and calculated from

$$
\alpha^{i d m i x}=\sum_{i=1}^{n} x_{i}\left[\alpha_{i}^{o}(T, v)+\alpha_{i}^{r}(\tau, \delta)+\ln x_{i}\right]
$$

where

$$
\begin{gathered}
\tau=\frac{T_{r e d}(x)}{T} \\
\delta=\frac{v_{r e d}(x)}{v}
\end{gathered}
$$

Thermodynamic Analysis. This paper selects the REFPRO9.0 issued by the National Institute of standards and Technology (NIST) calculation program and uses KW2 model parameters optimized by Akasaka R (as in Table 1 below) to calculate thermal physical properties and cycle performance of $\mathrm{R} 32$ and R1234ze refrigerant mixture in various ratio. The ratio of R32/ R1234ze is shown in Table 2.

Table 1. The $\mathrm{KW}_{2}$ model parameters in REFPRO9.0.

\begin{tabular}{ccccc}
\hline$\beta_{\mathrm{T}}$ & $\beta_{v}$ & $\gamma_{\mathrm{T}}$ & $\gamma_{v}$ & $\mathrm{~F}_{12}$ \\
\hline 1.00343 & 1.00586 & 0.977857 & 0.982707 & 0.265419 \\
\hline
\end{tabular}

Table 2. The mixing ratio of R32/ R1234ze. (mass percentage)

\begin{tabular}{cccccc}
\hline Number & 1 & 2 & 3 & 4 & 5 \\
\hline R32/R1234ze & $0.1 / 0.9$ & $0.3 / 0.7$ & $0.5 / 0.5$ & $0.7 / 0.3$ & $0.9 / 0.1$ \\
\hline
\end{tabular}

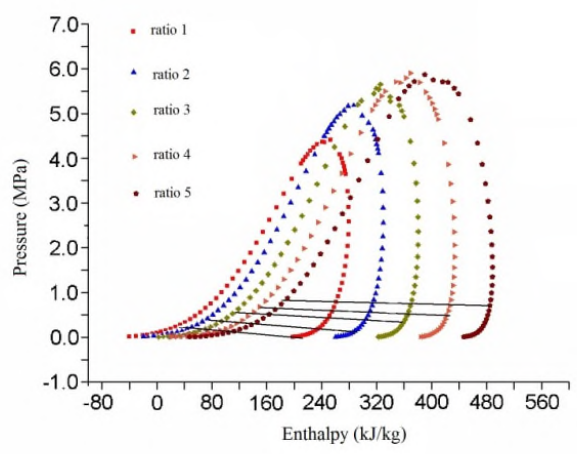

Fig. 1 P-h diagram of mixed refrigerant saturation property under different mixing ratio.

Using different ratio of mixed refrigerant as the research object, the saturation properties of P-H diagram is drawn in Fig. 1. With increasing content of R32 ratio, the critical point and critical temperature of the mixture rising gradually, and has an impact on the performance of the cycle and the saturated vapor of mixtures. By selecting the saturation temperature line $253.15 \mathrm{~K}$ as a baseline 
and comparing the curves in the graph, it is found that there exists temperature slip in the mixed refrigerant under different ratio, and with the increase of R32, temperature slip decrease gradually, reaching the maximum at ratio 1 . The main cause for this phenomenon is the non-azeotropic property of the R32 and R1234ze refrigerant mixture. The change of the ratio will lead to the latent heat of vaporization and result in changes in the scope of the two-phase region. These factors caused the temperature glide.

Theoretical Analysis of Cycle Performance. Conditions of the theoretical cycle calculation are chosen according to relevant requirements on heat pump hot water device test conditions in the national standard GB/T 231372008 [9]. For hygiene concern, the temperature of hot water needs to be higher than $55^{\circ} \mathrm{C}$ in daily use in urban area. For daily purposes like bathing and laundry, heat pump can provide hot water of $40^{\circ} \mathrm{C}$ or $45^{\circ} \mathrm{C}$, and can ensure a required flow, if there is no need for a water tank [10]. Because of the limited capacity of the laboratory, smaller-power units are chosen, and the research mainly works by the comparison of refrigerant performances. This paper selects $42^{\circ} \mathrm{C}$ as outlet water temperature of instant heat pump water heater and $52^{\circ} \mathrm{C}$ as the condensing temperature for the heat pump unit. The theoretical cycle calculation of mixed refrigerant and R32, R410A and R1234ze under different ratios is performed with standard condition. Test conditions are shown in Table 3. The state parameters including pressure, specific enthalpy, specific volume and specific entropy are calculated from REFPROP9.0. The calculation results are listed in Table 4.

When the mixed refrigerant are in Ratio 4 and Ratio 5, the heating coefficient is higher than $\mathrm{R} 410 \mathrm{~A}$, the volumetric capacity is close, the condensing pressure is lower, and the cycle performance is improved, which indicates a substitute for R410A. Considering the low GWP value and low exhaust pressure of R1234ze, Ratio 4, meaning the ratio $0.7 / 0.3$ of R32/ R1234ze can be the substitute for R410A.

Table 3. The condition of theoretical cycle calculation.

\begin{tabular}{|c|c|c|c|c|c|c|}
\hline Condition & $\begin{array}{c}\text { Dry bulb } \\
\text { temperature } /{ }^{\circ} \mathrm{C}\end{array}$ & $\begin{array}{c}\text { Wet bulb } \\
\text { temperature } /{ }^{\circ} \mathrm{C}\end{array}$ & $\begin{array}{c}\text { Condensing } \\
\text { temperature } /{ }^{\circ} \mathrm{C}\end{array}$ & $\begin{array}{c}\text { Evaporating } \\
\text { temperature } /{ }^{\circ} \mathrm{C}\end{array}$ & $\begin{array}{c}\text { Outlet } \\
\text { temperature } /{ }^{\circ} \mathrm{C}\end{array}$ & $\begin{array}{c}\text { overheating/ } \\
\text { supercooling } /{ }^{\circ} \mathrm{C}\end{array}$ \\
\hline $\begin{array}{c}\text { Text } \\
\text { condition }\end{array}$ & 20 & 15 & 52 & 10 & 42 & 5 \\
\hline
\end{tabular}

Table 4. Performance comparison of theoretical cycle.

\begin{tabular}{ccccccc}
\hline $\begin{array}{c}\text { Working } \\
\text { substance }\end{array}$ & $\begin{array}{c}\text { Evaporating } \\
\text { pressure/MPa }\end{array}$ & $\begin{array}{c}\text { Condensing } \\
\text { pressure/MPa }\end{array}$ & $\begin{array}{c}\text { Heat } \\
\text { output/ }\end{array}$ & $\begin{array}{c}\text { Volumetric } \\
\text { heat }\end{array}$ & $\begin{array}{c}\text { Specific } \\
\text { work/( kJ/kg) }\end{array}$ & COP \\
\hline R410A & 1.08 & 3.21 & 181.03 & 7300.40 & 30.18 & 5.99 \\
Ratio 1 & 0.37 & 1.26 & 121.21 & 2107.36 & 26.50 & 4.57 \\
Ratio 2 & 0.52 & 1.73 & 109.26 & 2231.74 & 31.54 & 3.46 \\
Ratio 3 & 0.69 & 2.21 & 162.46 & 3840.07 & 35.58 & 4.57 \\
Ratio 4 & 0.87 & 2.67 & 238.73 & 6289.10 & 39.24 & 6.08 \\
Ratio 5 & 1.03 & 3.09 & 264.90 & 7508.33 & 43.05 & 6.15 \\
\hline
\end{tabular}

\section{The Heat Pump Water Heater System Test}

Material. R1234ze, a kind of environmental friendly refrigerant, with 0 ODP value and 6 GWP value, and have a short atmospheric lifetime. But its latent heat is small and its evaporation pressure and thermal conductivity is low, which will lead to a decline in system performance coefficient. However, R32 has good thermal properties and transmission properties, whose theoretical COP and volumetric refrigerating capacity are higher $[3,4]$, and can be refrigerant mixture to improve the R1234ze thermodynamic and transport properties [5]. The result of theoretical calculation shows that the optimal ratio of R32/ R1234ze is 0.7/0.3, which can be the substitute for R410A. 
Methods. On the basis of the theoretical analysis of the thermal physical properties and cyclic performance of R32 and R1234ze mixed refrigerant, to make a contrast in practical operation, a practical test of the heat pump water heater with refrigerant mixture and R410A will be conducted. R410A special compressor is selected for the heat pump water heater, at the power of $1615 \mathrm{~W}$ under standard conditions; the condenser is a shell-and-tube heat exchanger; the evaporator is a finned tube heat exchanger with $7 \mathrm{~mm}$ tube diameter; temperature is collected with $\mathrm{T}$ type thermocouples; and a pressure transmitter is equipped in the inlet and outlet of the compressor. The schematic diagram of the experiment system is shown in Fig. 2.

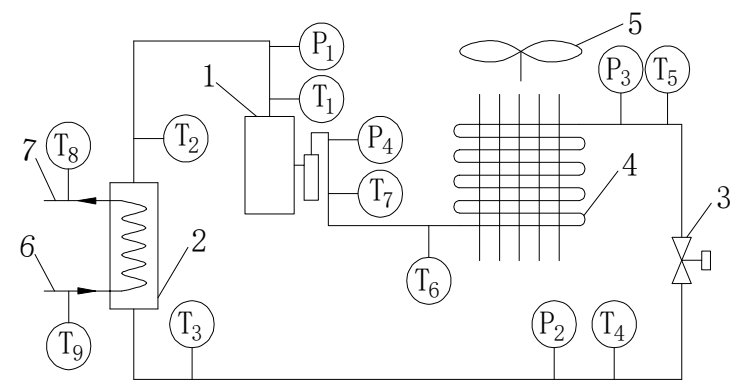

1. Compressor 2. Condenser 3. Electronic expansion valve 4. Evaporator 5. Fan 6. The inlet tube of condenser 7. The outlet tube of condenser

Fig. 2 Schematic diagram of experimental system.

The Experimental Test Conditions. According to the provisions of the national standard GB/T 23173-2008, besides the standard condition, another five conditions are set in this test. Total six conditions are shown in the Table 5, the standard condition is number 4.

Table 5. The test conditions of heat pump water heater.

\begin{tabular}{ccccc}
\hline Text condition & $\begin{array}{c}\text { Dry bulb } \\
\text { temperature } /{ }^{\circ} \mathrm{C}\end{array}$ & $\begin{array}{c}\text { Wet bulb } \\
\text { temperature } /{ }^{\circ} \mathrm{C}\end{array}$ & $\begin{array}{c}\text { Inlet water } \\
\text { temperature } /{ }^{\circ} \mathrm{C}\end{array}$ & $\begin{array}{c}\text { Water } \\
\text { flow/(L/min) }\end{array}$ \\
\hline Condition 1 & 7 & 6 & 10 & 5 \\
Condition 2 & 10 & 7 & 10 & 5 \\
Condition 3 & 15 & 12 & 10 & 5 \\
Condition 4 & 20 & 15 & 15 & 5 \\
Condition 5 & 25 & 20 & 20 & 5 \\
Condition 6 & 30 & 25 & 25 & 5 \\
\hline
\end{tabular}

\section{Experimental Results and Performance Analysis.}

Analysis of the compressor's suction and discharge temperature and pressure. The suction and discharge temperature and pressure of mixed refrigerant and R410A under different conditions are shown in Fig. 3 and Fig. 4 respectively. With the increase of ambient temperature and inlet water temperature, the suction and discharge temperature and pressure of $\mathrm{R} 410 \mathrm{~A}$ are increasing. The suction and discharge pressure of R32 and R1234ze mixture are lower than that of R410A, which is mainly due to the influence of R1234ze; the suction and discharge temperature and pressure of pure R1234ze both are lower than those of R410A. 


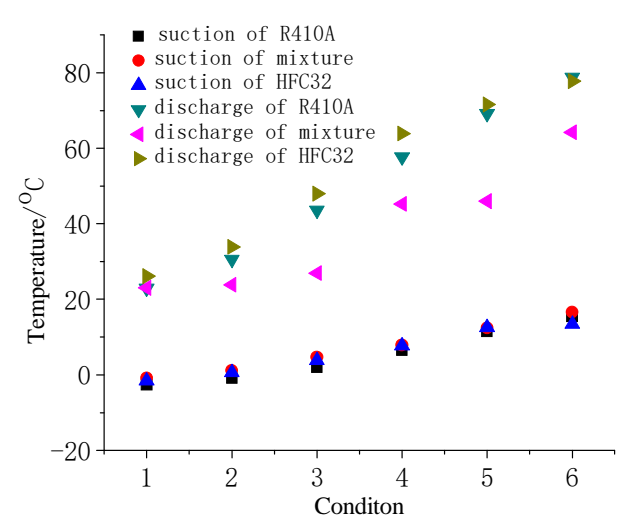

Fig. 3 The suction and discharge temperature of pressure of compressor under different conditions.

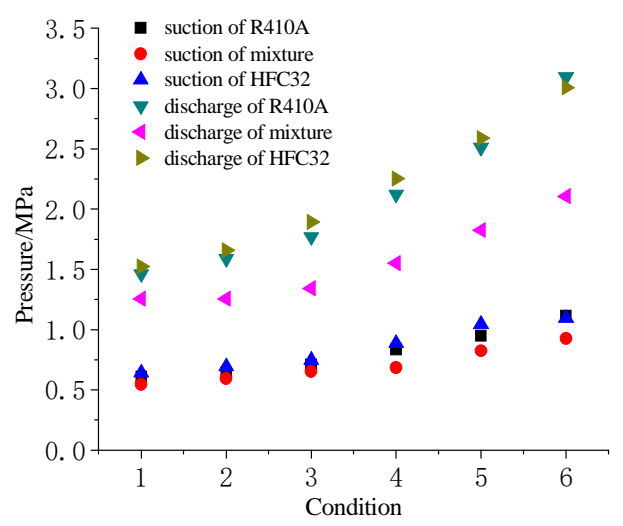

Fig. 4 The suction and discharge compressor under different conditions.

When the ambient temperature and water temperature increase, the condensing effect of the refrigerant becomes worse, resulting in the rise of condensation pressure and the increase of compressor discharge pressure, whilst the compressor suction pressure almost stays the same. Therefore, the pressure ratio increases in the high temperature conditions. However, the change of pressure ratio of R32 and R1234ze refrigerant mixture is obviously smaller than that of R410A. Lower pressure is a guarantee for the safe operation of the unit.

Analysis of compressor power and COP. As shown in Fig. 5 and Fig. 6, the COP value of R32 and R1234ze mixture is higher than that of R410A, with the maximum value 3.56 for R410A, and the maximum value 4 for the mixture. With the increase of temperature, the discharge temperature and pressure becomes higher, the heat transferring becomes worse, and compressor power becomes larger. Under condition 4/5/6, the COP values of the refrigerant mixture and R410A both show a decreasing trend, but the trend for R410A is more obvious. This is because the suction and discharge pressure of mixed refrigerant is lower and the slope of isentropic of the cyclic system is larger in the overheated zone in the pressure enthalpy diagram. With the increase of environmental temperature, compressor power changes slowly. When the heat transfer changes little, the COP of the system decreases more slowly.

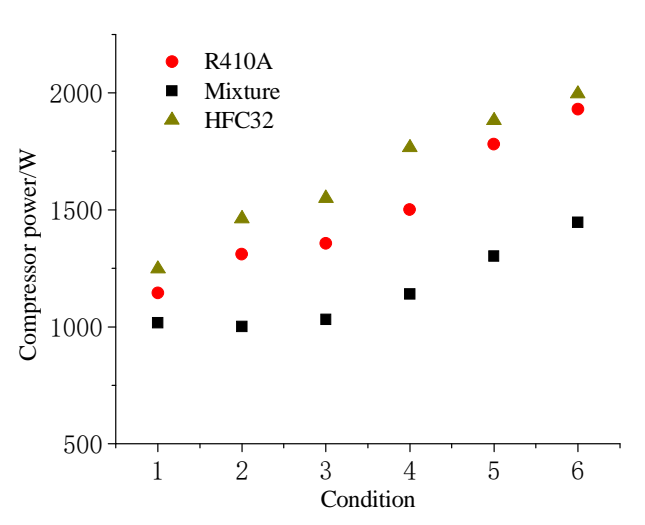

Fig. 5 The compressor power under different condition.

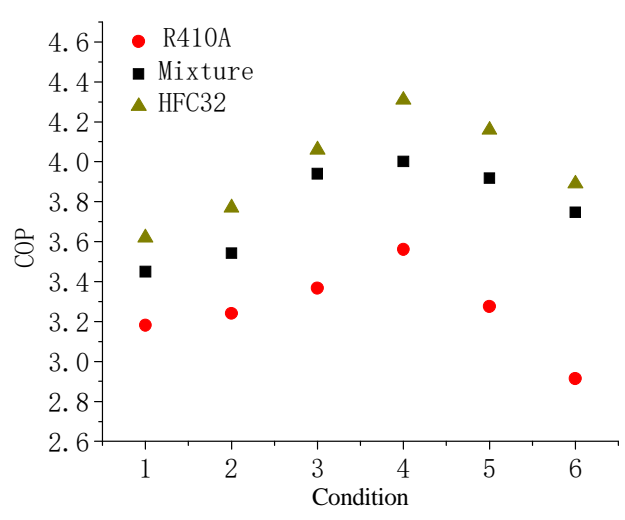

Fig. 6 COP of the system under different conditions.

\section{Summary}

This paper calculates the cyclic performance and thermophysical properties of R32 and R1234ze mixed refrigerant in different ratios, and finds that when the ratio of R32 and R1234ze is $0.7 / 0.3$, the volumetric capacity is closed to R410A, and the heat coefficient is higher; the condensing pressure is lower, and the cycle performance is improved. 
An experimental study is conducted on the application of R32 and R1234ze mixed refrigerant and $\mathrm{R} 410 \mathrm{~A}$ in heat pump water heater in the ratio of $0.7 / 0.3$, analyzing the operating parameters of R32 and R1234ze mixed refrigerant and R410A heat pump water heater under different conditions. The experiment results show that the operating pressure of R32 and R1234ze mixed refrigerant system is lower than that of R410A system, which is safer for the operation, and the outlet water temperature is similar with higher COP. And the advantage of R32 and R1234ze mixed refrigerant system is more obvious under high-temperature operation conditions, which provide the feasible reference for refrigerant heat pump water heater replacement.

\section{References}

[1] Z. Yang, X. Wu, H. J. Yin, et al. Analysis on Alternatives for HCFCs with Low Greenhouse Effect, J. Refrig. 32(1) (2011) 1-6.

[2] Regulation (EU) No.517/2014 of the European parliament and of the council of 16 April 2014 on fluorinated green-house gases and repealing regulation (EC) No 842 /2006, Official J. Eur. Union, 150 (2014) 195-230.

[3] S. Y. Yang, Q. Wang, L. M. Tang, et al. Review of the Application of R32 on Air Conditioners and Heat Pump Systems, J. Refrig. 34(6) (2013) 59-68.

[4] Z. Tian, B. Gu, T. Wang, et al. Calculation Model of Thermodynamic Properties of Saturated Liquid for HFC-32 Refrigerant, J. Refrig. 34(2) (2013) 28-32.

[5] Y. Onaka, A. Miyara, K. Tsubaki, et al. Cycle evaluation of refrigerant mixtures of CO2/ DME and HFC-32 / HFO1234ze(E), /The 23rd IIR International Congress of Refrigeration. Prague, Czech Republic: Chalmers Publication Library, 2011.

[6] A. H. Md., O. Yoji, M. M. A. Hasan, M. Akio, Heat transfer during evaporation of R1234ze(E), R32, R410A and a mixture of R1234ze(E) and R32 inside a horizontal smooth tube, Int. J. Refrig. 36(2) (2013) 465-477.

[7] A. H. Md., Y. Onaka, A. Miyara, Experimental study on condensation heat transfer and pressure drop in horizontal smooth tube for HFO-1234ze(E), HFC32 and R410A, Int. J. Refrig. 35(1) (2012) 927-938.

[8] A. Ryo, Thermodynamic property models for the difluoromethane (R-32) + trans-1, 3, 3, 3-tetrafluoropropene (R-1234ze(E)) and difluoromethane+2, 3, 3, 3-tetrafluoropropene (R-1234yf) mixtures. Fluid Phase Equilibria, 358 (2013) 98-104.

[9] National Standardization Committee of China, GB/T23137 - 2008 Domestic and similar heat pump water heater national standard, Beijing: China Standard Press, 2008.

[10] Y. T. Ma, B. M. Dai, Discussion on Outlet Water Temperature and Energy Efficiency Standard of Air-source Heat Pump Water Heater, Refrig. Air-condition. 8 (2014) 123-127. 